\section{Intratabuläre Fibrillen in den Mitochondrien von Streptotheca thamesis}

\author{
KLAus Esser \\ Hygiene-Institut der Universität Marburg/Lahn \\ (Z. Naturforschg. 22 b, 994 [1967] ; eingegangen am 3. Juli 1967)
}

In den letzten Jahren wurde wiederholt über fibrilläre Einschlußkörper in Mitochondrien verschiedener Herkunft berichtet ${ }^{1-9}$. Diese Strukturen werden beschrieben als "helical filaments", "microcylinders", "crystallised tubuls", o. ä. und finden sich entweder in der Mitochondrienmatrix ${ }^{6-9}$ oder innerhalb der Mitochondriensacculi ${ }^{1-5}$.

Im folgenden werden vergleichbare Beobachtungen bei Streptotheca thamesis mitgeteilt. Die Mitochondrien dieser Diatomee gehören zum tubulären Bautyp (siehe Abb. 1), für den nur ein einzelner Befund über ein Vorkommen fibrillärer Strukturen in der Matrix, nicht in den Tubuli, vorliegt ${ }^{6}$. Bei Streptotheca liegen jedoch eindeutig intratubuläre Fibrillen vor ( $\mathrm{iF}$ in Abb. ${ }^{*}$ ). Bei hoher Vergrößerung wird deutlich, daß jede Fibrille aus zwei Einzelfilamenten besteht, die - zumindest streckenweise - zu einer Helix locker umeinander gewunden sind. Der Durchmesser dieser Helix beträgt ca. $140-150 \AA$, der Durchmesser des Einzelfilaments ca. $30-40 \AA$. Als größte Länge der gesamten Fibrille wurde ca. $0,5 \mu$ gemessen, aber dieser Wert schwankt naturgemäß mit der sehr variablen Länge des jeweiligen Tubulus, den eine solche Fibrille in Längsrichtung durchzieht. In Querschnitten wurden Fibrillenzahlen von $1-7$ pro Tubulus gefunden. Es ist aber hervorzuheben, daß der größte Teil der Tubuli eines Mitochondriums keine der beschriebenen Fibrillen enthält. $\mathrm{Ob}$

1 O. Behnke, Exp. Cell Res. 37, 687 [1965].

2 H. S. Lin, J. Cell Biol. 25, 435 [1965].

3 E. Mugnaini, J. Cell Biol. 23, 173 [1964].

4 W. R. Richter, R. J. Stein u. L. E. Blockus, Vi. Intern. Congress for Electron Microscopy, Kyoto 1966, Vol. II, Biology, 615, Maruzen Co. Ltd., Tokyo 1966.

5 D. Svoboda u. J. Higginson, Amer. J. Pathol. 45, 353 [1964].

* Abb. 1 s. Tafel S. 994 b. ein ganzes Mitochondrium frei von Fibrillen sein kann, ließe sich nur an Hand von ausgedehnten Schnittserien klären. Eine abnorme Strukturveränderung ganzer Mitochondrien oder einzelner Sacculi im Zusammenhang mit dem Auftreten der Fibrillen wurde bei Streptotheca nicht beobachtet, im Gegensatz zu den meisten der angeführten Untersuchungen bei anderen Objekten.

Die chemische Natur der fraglichen Fibrillen blieb bisher ungeklärt. Verschiedene Hinweise, die auf ein Protein deuten, werden diskutiert ${ }^{1,3,9}$, und seit der Entdeckung der Mitochondrien-DNS ${ }^{10}$ steht auch diese als Baustein der fibrillären Strukturen zur Debatte ${ }^{3}$. Ein Beitrag zur Klärung dieses Problems wurde bei Streptotheca versucht: Ganze Diatomeen wurden nach kurzer Vorfixierung in Glutardialdehyd, $\mathrm{OsO}_{4}$ oder beiden Fixantien einer Behandlung mit DNAse, RNAse oder Pepsin unter geeigneten Bedingungen ausgesetzt. Unter mehreren der gewählten Versuchsbedingungen ließ sich die Einwirkung der beiden Nucleasen auf verschiedene Zellstrukturen nachweisen ${ }^{11}$, während die intratubulären Mitochondrienfibrillen nicht angegriffen wurden. Dies war jedoch eindeutig nach 4-8-stdg. Pepsinbehandlung der Fall, die unter bestimmten Bedingungen zu einem Abbau der fraglichen Fibrillen führte. Hiermit ist - zumindest für Streptotheca thamesis eine Proteinnatur der intratubulären Mitochondrienfibrillen nachgewiesen.

Eine ausführlichere Darstellung wird in größerem Zusammenhang erscheinen.

Fräulein K. Vester danke ich für ausgezeichnete Mitarbeit. Eine Arbeitsmöglichkeit am Elmiskop I a des Botanischen Instituts der Universität Marburg verdanke ich den Herren Professor Dr. W. Nultscr und Professor Dr. H. A. v. Stosch, dem ich auch für die Bereitstellung des Untersuchungsmaterials herzlich danke.

${ }^{6}$ H. FALK, Z. Pflanzenphysiol. 53, 456 [1965].

7 A. KJaerheim, Exp. Cell Res. 45, 236 [1967].

8 K. Kurosumi, T. Matsuzawa u. N. Watari, J. Ultrastructure Res. 16, 269 [1966].

9 E. Mugnaini, J. Ultrastructure Res. 11, 525 [1964].

10 M. K. Nass u. S. Nass, J. Cell Biol. 19, 593 [1963].

11 KL. Esser, in Vorbereitung. 


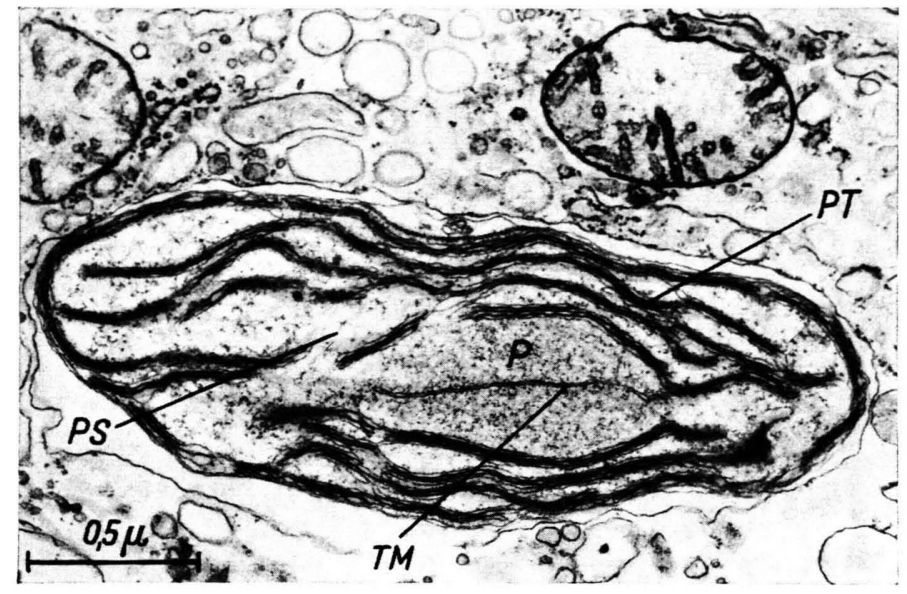

Abb. 1. Längsschnitt durch einen Plastid von Streptotheca thamesis. $\mathrm{P}=$ Pyrenoid, $\mathrm{PT}=$ Plastidenthylakoide, $\mathrm{PS}=$ Plastidenstroma, TM=,thylakoide Membran“ des Pyrenoids. Fixierung in Glutardialdehyd gefolgt von $\mathrm{OsO}_{4}$, Kontrastierung mit Uranylacetat gefolgt von Bleicitrat. Vergr. 35000 -fach.

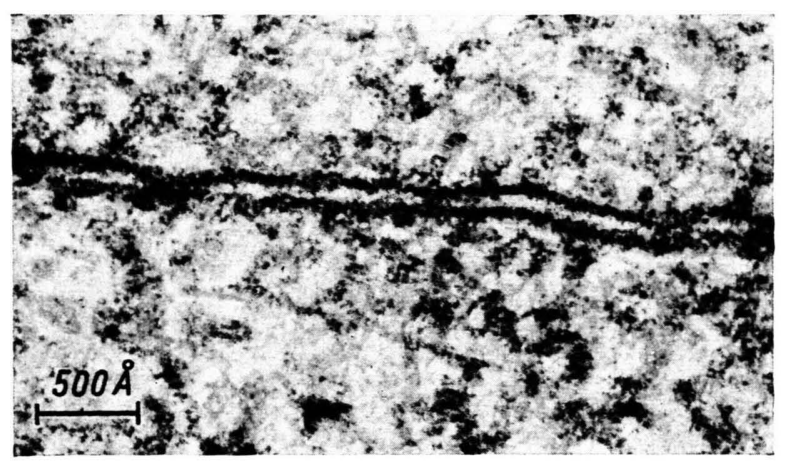

Abb. 2. Schnitt durch die ,thylakoide Membran“ des Pyrenoids, ohne DNAse-Behandlung, Fixierung und Kontrastierung wie bei Abb. 1. Vergr. 200000 -fach.

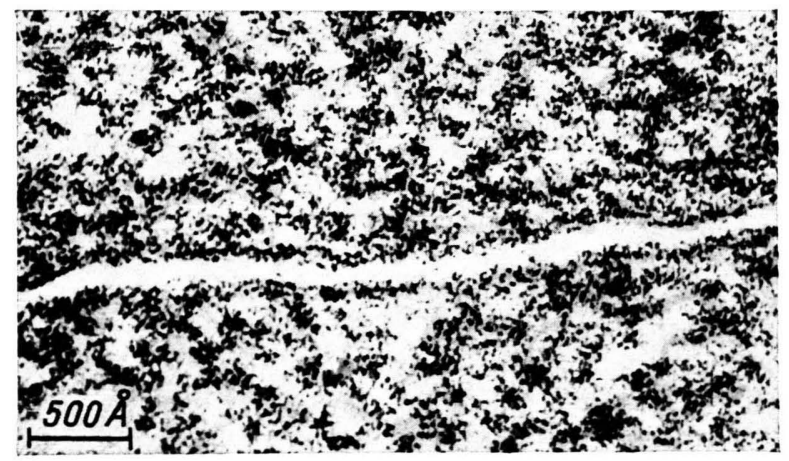

Abb. 3. Schnitt durch die Region der ,thylakoiden Membran“ nach 8-stdg. DNAse-Behandlung. Vorfixierung in Glutardialdehyd, DNAse-Inkubation, Nachfixierung in $\mathrm{OsO}_{4}$, Kontrastierung wie bei Abb. 1. Vergr. 200000 -fach. 
K. Esser, Intratabuläre Fibrillen in den Mitochondrien von Streptotheca thamesis. (S. 994)

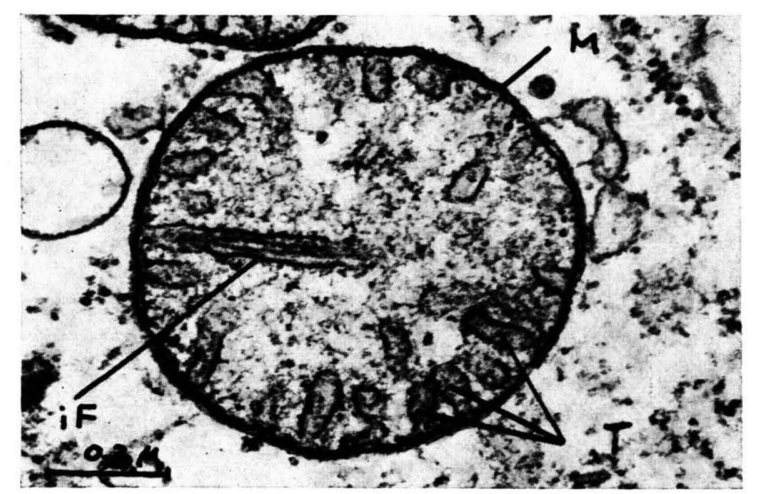

Abb. 1. Querschnitt durch ein Mitochondrium von Streptotheca thamesis: $\mathrm{M}=$ äußere und innere Mitochondrienmembran, $\mathrm{T}=$ Tubuli, iF $=$ Tubulus mit 2 Fibrillen; Fixierung in Glutardialdehyd/O $\mathrm{sO}_{4}$, Kontrastierung mit Uranylacetat/ Bleicitrat. Vergrößerung 60000 -fach. 